\title{
Exilio y democracia Un viaje de exploración sobre una vida política e intelectual
}

\author{
Hugo Quiroga ${ }^{(*)}$
}

\section{Resumen}

El artículo es la reescritura, corregida y ampliada, de un anterior escrito homenaje dedicado a Ricardo M. Falcón. El autor, amigo y compañero de travesía en la experiencia del exilio en Europa y del retorno a la Argentina luego de la última dictadura cívico-militar, se propone presentar la trayectoria política e intelectual de Falcón y la va enlazando con una empresa también compartida durante la transición democrática, la que los vincula a la reconstrucción de la vida académica en las universidades argentinas y, en especial, en la Universidad Nacional de Rosario.

Palabras clave: Intelectuales; Exilio; Democracia; Universidad.

Exile and democracy: A explorative journey on a political and intellectual life

\begin{abstract}
The article is a corrected and broadened rewriting of an earlier text, a homage to Ricardo $M$. Falcón. The author, a friend and journey partner in the experience of exile in Europe and of return to Argentina after the last dictatorship, intends to present Falcón's political and intellectual trajectory and ties it to a shared enterprise during the transition to democracy, which links them to the reconstruction of academic life in Argentinian universities and the Universidad Nacional de Rosario in particular.
\end{abstract}

Key Words: Intellectuals; Exile; Democracy; University.

\footnotetext{
${ }^{(*)}$ Doctor en Filosofía. Profesor Honorario de Ciencia Política y Relaciones Internacionales (Universidad Nacional de Rosario). Investigador superior del CIUNR (consejo de Investigaciones de la UNR). Director de la revista Estudios Sociales (Universidad Nacional del Litoral). Mail: hquiroga@,fibertel.com.ar
} 


\section{Exilio y democracia}

\section{Un viaje de exploración sobre una vida política e intelectual ${ }^{1}$}

\section{Introducción}

Una circunstancia especial me permite revisar y ampliar un texto de homenaje a Ricardo Falcón, escrito tiempo después de su fallecimiento. Ahora, un nuevo homenaje de la Revista del CIESAL, me concede, por así decirlo, una nueva visita al primer texto, que ya implicaba un viaje de exploración sobre la vida política e intelectual de Ricardo Falcón. Por cierto, ese itinerario incluye nuestra profunda y placentera amistad de tantos años.

En la vida de Ricardo se pusieron en juego sus virtudes, pero también sus contradicciones, como en todos nosotros. Un rasgo fundamental lo caracterizaba: el clima y el ambiente de comunicación y trabajo que creaba con sus amigos, colegas y estudiantes. El centro de ese ámbito era la palabra, la discusión y el debate, que en general se generaba por fuera del ejido universitario. Los temas constituían un repertorio variado: la vida, las pasiones, el exilio, la política, el movimiento obrero, el socialismo, los proyectos de investigación, las tesis doctorales, todo con un acompañamiento crítico de sus argumentos. En este ejercicio intelectual, donde había también mucho de ficción y anécdotas repetidas, Ricardo hizo una libre elección de vida, que lo llevó a caminar por un sendero angosto en sus últimos años, a pesar de su inmenso talento.

Mis apreciaciones giran ahora en torno al subtítulo de la nota: "Un viaje de exploración sobre una vida política e intelectual". Ese viaje comienza con la amistad, la que mantuvimos con Ricardo Falcón. "Amistad", en el sentido literal del término, de apego mutuo y afecto desinteresado y recíproco. Una amistad profunda y sincera de 33 años (aunque Ricardo insistía en que era más extensa, pues, según él, ya nos habíamos conocido antes del exilio compartido), que resistió todas las pruebas que nos tocó vivir, en Francia y en la Argentina.

Con ese punto de partida, en este breve viaje de exploración podemos reconocer varias etapas en la vida de Ricardo. En la época del militante político, fue un reconocido dirigente estudiantil de Política Obrera, agrupación de origen trostkista. Colaboró como militante (y más tarde fue un estudioso) de la huelga de Villa Constitución, de vibrante repercusión en la vanguardia obrera revolucionaria de entonces. La huelga se extendió durante dos meses, bajo el gobierno constitucional de Isabel Perón, en 1975. Yo militaba en la Organización Comunista Poder Obrero (OCPO), más conocida como Poder Obrero, una agrupación antistalinista. Creo que nos

\footnotetext{
${ }^{1}$ El presente texto es una reescritura del trabajo publicado en la Revista Estudios Sociales 40, Revista Universitaria Semestral, 2011, Ediciones UNL, con el título "In vino veritas. Un viaje de exploración sobre una vida política e intelectual".
} 


\section{Hugo Quiroga}

tratamos en esa época, en medio del conflicto, pero en ese momento nunca llegamos a ser amigos.

Ricardo se proclamaba un luxemburguista (y se jactaba de ello), partidario de la huelga de masas y de la insurrección, que descreía de las "vanguardias iluminadas" que preparan a las masas, a través de la teoría del foco, para la toma del poder. En la hondura y en la superficie, concientes o inconcientes, de una manera o de otra, "todos", que incluye a las organizaciones armadas y a las que no lo eran, nos considerábamos como vanguardistas. El telón de fondo de este relato es un clima de época, que provenía de los tiempos de la revolución cubana y del "Cordobazo", en 1969, de la movilización de masas, del entusiasmo de los sectores juveniles por la idea de revolución, de la existencia de una vanguardia obrera industrial combativa, y de otros sectores contestatarios de las clases populares y medias, de los años sesenta y setenta. Todo ello constituía un horizonte de sentido por sí mismo.

Si bien Ricardo militó a favor de la construcción de un partido obrero revolucionario, nunca comulgó con la metodología de la lucha armada de las organizaciones guerrilleras, aquella de los "pequeños grupos". Era, en cambio, partidario de la violencia política, en el sentido soreliano de destrucción de las cadenas. Creía en la violencia de masas que se expresaba en la huelga general y la lucha insurreccional. En ese período no era un pacifista. En la etapa del exilio nace y crece, entonces, nuestra intensa amistad, alimentada por el afecto y la confianza recíprocos. Esa amistad fue asimismo fortalecida por el nacimiento del hijo de Ricardo, Miguel y, al poco tiempo, el de mi hijo Nicolas. Construimos ahí un zócalo de sentimientos comunes.

Si bien cada uno pensaba por sí mismo, dos temas centrales nos unieron al comienzo del destierro: la lucha por la democracia en la Argentina y la defensa de los derechos humanos, luego de las atrocidades cometidas por la dictadura militar de 1976. Más adelante, en sendas discusiones, logramos revisar nuestra concepción de democracia, aquella que la catalogaba exclusivamente como formal y burguesa. Además de discutir un tema que nos apasionaba, "las mentiras en política", tanto en Francia como en la Argentina. Un tema que se volvía atractivo, porque las mentiras en política son frecuentes, principalmente cuando los hombres políticos están en campaña electoral. Pero también con cierta ironía decíamos que nosotros (los revolucionarios) nos mentíamos a nosotros mismos, nada más que por una buena causa: la revolución. La mentira resultaba un término ambiguo, que podía ser justificada.

Las progresivas afinidades políticas nos acercaban a un pensamiento más común. La propia experiencia de la historia política argentina, sumada a la de otros países, del Este (principalmente la disidencia de los regímenes totalitarios), y del Oeste, a nuevas lecturas, a la relectura de los clásicos del marxismo, sin una impronta militante, nos condujo a rechazar las tentaciones del partido único, a reivindicar la libertad política, la igualdad social, la tolerancia, 
"Exilio y democracia. Un viaje de exploración sobre una vida política e intelectual"

la disidencia, el pluralismo, y la sucesión pacífica y competitiva del poder. En mi caso, quizá más que en Ricardo, me influyó enormemente la disidencia de Václav Havel (primer presidente de la República Checa) que se opuso a la invasión de Checoslovaquia instrumentada por la Unión Soviética en 1968, defensor de los derechos humanos, que fue encarcelado en numerosas oportunidades en la década del setenta. Fue uno de los fundadores del movimiento Carta 77. Con Ricardo aprendimos igualmente que sin ciudadanos no existe la política, sin ciudadanos libres y con derechos, lo mismo que pasaba en los países del Este ocurría en las dictaduras latinoamericanas, particularmente en la de Argentina de 1976.

Recuerdo, al pasar, algunos libros que contribuyeron a la revisión de mi dogmatismo y de una lectura sesgada del marxismo, propia de la militancia política de izquierda, que provocaron una apertura mental. Il Manifesto. Tesis de una disidencia comunista, de Rossana Rossanda (a cargo de la presentación), publicado en español en 1973. Los textos que se podían conseguir, traducidos al español o al francés, de un "marxista olvidado" (la expresión le pertenece a Michel Löwy), censurado por la burocracia comunista: Antonio Gramsci. En la Argentina, el pionero de esas traducciones para el mundo hispanoamericano había sido Pancho Aricó. Fueron también lecturas obligadas las obras del marxista estructuralista Nicos Poulantzas, y desde otra perspectiva del marxismo, las de Perry Anderson, autor, entre tantas obras, de Sur Gramsci, versión francesa de 1978. Igualmente el libro de Agnes Heller y Ferenc Feher, Marxismo et démocratie. Au-dela du "socialismo réel", de 1981. Una obra de gran impacto en el universo de la izquierda fue el libro de André Gorz, Adieux au proletariat, de 1980, que nos introdujo en un gran debate con Ricardo. Mi lamento intelectual por haber arribado tardíamente a la producción de Claude Lefort y Cornelius Castoriadis. Ricardo leyó otras cosas, sobre el mundo del trabajo, por ejemplo, la obra de Edward Thompson, mientras continuaba con sus estudios universitarios en la carrera de historia.

Estas y otras lecturas, que estimularon nuestras revisiones, fueron los gérmenes que nos llevaron a una discusión central: acerca de la constitución de un "sujeto predeterminado", el proletariado, que ya no aparecía como el sujeto histórico de la revolución, representado por un partido único. Las experiencias de dominación totalitaria estaban a la vista tanto en la Unión Soviética como en China (aun cuando en este país el sujeto de la revolución había sido el campesinado). Este debate, de ningún modo pretencioso, nos hizo comprender que era imposible la vía al socialismo sin instituciones democráticas. Tal vez este recorrido acentuó el estudio de Ricardo por la historia del movimiento obrero, antes que seguir pensando en la creación de un partido proletario. ¿De qué nos despedíamos? De un tipo de utopía que había derivado en regímenes totalitarios, y de otro tipo de utopía que pensaba que el partido revolucionario, aun cuando alegaba su vinculación orgánica con las masas, se pensaba como partido único, como una 


\section{Hugo Quiroga}

maquinaria con poderosas tecnologías de poder, ignorando la complejidad de las sociedades contemporáneas, su estructura pluralista y contestataria, que requería de instituciones democráticas para procesar los conflictos y transmitir el poder. Nos despedíamos, en fin, de una izquierda dogmática y sectaria incapaz de dialogar con otras corrientes de pensamiento de izquierda.

El exilio fue también una posibilidad para nosotros; ambos pudimos seguir estudiando. Creo que en París nace una vocación académica muy fuerte en Ricardo; su incansable trabajo de archivo sobre la historia del movimiento obrero que realizó en la biblioteca de Ámsterdam, y su doctorado en Historia de l'École des Hautes Études en Sciences Sociales de Paris, que finalmente lo termina en la Argentina en el año 1985, momento en el que viaja a Francia para la soutenance de la tesis.

El exilio nos encontró también unidos en la organización y participación de diferentes grupos de exiliados, que a la distancia y de diferentes maneras, resistíamos a la dictadura militar. Pienso, entre otros, en el Grupo por la Democracia y la Libertad en la Argentina, constituido, además de los parisinos, por exiliados argentinos residentes en otros países de Europa. Otro, de corta duración y sin ninguna proyección, fue el de los activistas y militantes obreros en el exilio, que tuvo su reunión cumbre en Milano, auspiciada por las tres centrales sindicales de Italia. Allí pude comprobar, una vez más, sus dotes de orador y polemista, siempre de pie, al final de sala, con el cigarrillo en la mano, y con una buena dosis de adrenalina que lo mantenía en constante movimiento.

Cuando promediaba el exilio, participamos de la "Cena de los Jueves", convocada por Hipólito Solari Irigoyen (con quien Ricardo entabló una sincera amistad), libre y abierta, que se transformó en un ámbito placentero de reunión y encuentro de comensales argentinos, con invitados especiales, muchos de los cuales eran dirigentes políticos, intelectuales, o militantes de los derechos humanos, que vivían en la Argentina. Desde luego, los ejes centrales de esas conversaciones eran el fin de la dictadura y la transición a la democracia.

Antes de pasar a la tercera etapa, la del regreso, me interesa resaltar dos cuestiones primordiales. La primera, fue una discusión prolongada en el tiempo sobre qué hacer con nuestro pasado, cuando la idea de revolución había fracasado. ¿Cuál era el sentido de nuestra identidad? Ricardo se mostraba muy renuente a abandonar su rol de militante político (aunque en los hechos ya se había producido) y de asumir un rol de intelectual con proyección pública. La palabra "intelectual" en ese momento no le satisfacía mucho, sin embargo, más tarde, en la Argentina, se asumiría como un intelectual del socialismo democrático. La segunda, la guerra de Malvinas nos encontró juntos, en notable minoría, con las mismas posiciones. Nos pronunciamos a favor 
"Exilio y democracia. Un viaje de exploración sobre una vida política e intelectual"

de la paz, y en contra de una guerra iniciada por la dictadura criminal con el único objetivo de recomponer ante la sociedad su resquebrajado orden autoritario.

De regreso a casa, con la renacida democracia, pudimos observar los cambios producidos, lo que habíamos sido, lo que éramos y lo que podíamos ser. Desde el punto de vista intelectual, Ricardo publicó su primer libro, de gran impacto entre los estudiosos del tema, titulado Los orígenes del movimiento obrero (1857-1899), en la Biblioteca Política Argentina del Centro Editor de América Latina, en 1984. En mi caso, publiqué en la misma editorial mi primer libro Estado, Crisis económica y poder militar (1880-1981), en el año 1985. Pero algo mucho más novedoso y desconocido es que con Ricardo publicamos un solo texto juntos, a pesar de tantos años de amistad y sintonía política e intelectual. Fue un trabajo extenso, de más de cien páginas, denominado "Contribución al estudio de la evolución ideológica del partido comunista argentino (1960-1984)", editado en la serie de Documentos del Programa FLACSOSANTIAGO DE CHILE, “Contribuciones”, No 50, noviembre de 1987.

De la misma manera, ingresamos como profesores de la Universidad Nacional de Rosario, y al poco tiempo cada uno revalidó ese ingreso por sendos concursos públicos. Ricardo primero desarrolló sus actividades académicas en la Facultad de Humanidades y Artes, y más tarde en la Facultad de Ciencia Política y RR.II. Yo comencé enseñando Derecho Político en la cátedra de Oscar Blando y poco después de mi concurso en 1986 me instalé definitivamente en la cátedra de Teoría Política II de la mencionada Casa de Altos Estudios.

Desde el punto de vista político, con Ricardo fuimos admiradores de Raúl Alfonsín, entre otras cosas, por el juicio a las Juntas Militares, la creación de la CONADEP, que el peronismo no quiso integrar. Sabíamos que con ello no sólo se juzgaba a los genocidas, sino que se sentaba en el banquillo de los acusados, ante un tribunal civil de la democracia, a los actores políticos que durante cincuenta años habían dominado, de una manera u otra, la política argentina, entre 1930 y 1983. El exilio nos privó de la posibilidad de votar por Raúl Alfonsín, que se enfrentaba a un adversario con amplias posibilidades de triunfo, como Ítalo Luder, quien había declarado que no derogaría la "ley de autoamnistía", salvoconducto dictado por los militares en retirada. Esa posición implicaba la renuncia a juzgar a la dictadura militar por las atrocidades cometidas. A estas alturas, no se puede saber el cauce que hubiera tomado la flagrante de violación de los derechos humanos, si el candidato Luder hubiera triunfado en las elecciones de octubre de 1983. Ningún análisis contrafáctico es posible.

Junto a otros compañeros de distintos orígenes políticos, creamos el Club de Cultura Socialista de Rosario (bajo el impulso principal de Ricardo), de corta vida, pero que dejó una marca perdurable. Fue durante un tiempo, un lugar de reencuentro y de convite para discutir la 


\section{Hugo Quiroga}

transición democrática, pluralista y abierto, con el fin de ir asumiendo más lúcidamente el futuro individual y colectivo, con amigos y colegas universitarios.

En este largo viaje, el rol de Ricardo como profesor, hasta el final de su vida, es algo que todos recordaremos con cariño y admiración. Su preocupación e interés por la formación de recursos humanos, equipos de trabajo y de investigación es destacable, en una época en que la universidad pública retomaba la dinámica y jerarquía que había perdido acosada por la dictadura, sobre todo en el campo de las ciencias sociales y humanas. Su actitud generosa con sus amigos, colegas y estudiantes. Su biblioteca estaba a disposición de todos, así como también el tiempo que le dedicaba a los asuntos que trataba con cada uno de interlocutores. Su capacidad de escucha era ilimitada. Siempre interesado por los temas académicos, pero apasionado por la política.

Los diálogos en los bares se hicieron famosos. Esos ámbitos sociales se convirtieron en una institución, en un lugar de trabajo y de amistad. Siempre abierto al debate libre y fecundo, con la izquierda, en sus diferentes versiones, con el radicalismo, el peronismo, el anarquismo. Por eso, en la presentación de su libro La Barcelona Argentina, del año 2005, publicado en Laborde Editor, Ricardo pudo reunir una plural confluencia de disímiles pensamientos políticos. Nadie más podía ser el autor de semejante hazaña. Hoy, no puedo dejar de recordar a Poli Laborde, el editor, un amigo en común, que partió hacia el silencio en octubre de 2021.

Se preciaba de ser un promotor, junto a Pancho Aricó, de la unidad del socialismo en la Argentina. Se afilió al Partido Socialista Democrático, sin la intención de ser un político práctico. No se imaginaba el socialismo sin la estrecha combinación de los principios de libertad política e igualdad social. No creo que le hubiera gustado el rótulo de "intelectual gubernamental", por eso no hubiera aceptado nunca un puesto de gestión pública. Sabíamos que el intelectual se define por su capacidad de crítica, y si él se hubiera enrolado en un espacio de gestión pública, ese papel se habría desvanecido.

Ricardo tenía tanta capacidad y facilidad para construir como para desarmar empresas intelectuales y académicas. Algunas perduraron. Fue fundador de centros de estudios, y de revistas, entre ellas mencionamos Estudios Sociales y los Cuadernos del CIESAL, publicación del "Centro Interdisciplinario de Estudios Sociales Argentinos y Latinoamericanos", creado por Resolución Rectoral N 1039/1990. La razón por la cual crea la Revista del CIESAL, cuando ya existía Estudios Sociales, la hallamos en la editorial del primer número. Destaco el No 9 de Cuadernos de CIESAL, número especial de enero-junio 2011, en homenaje a un año de su muerte, en el que publicaron trabajos inéditos. En esta tarea de emprendimientos editoriales no quiero dejar pasar que fue director de la revista Temas y Debates de la Facultad de Ciencia Política y RRII de la Universidad Nacional de Rosario. 
"Exilio y democracia. Un viaje de exploración sobre una vida política e intelectual"

Ricardo fue un intelectual de la causa socialista, un estudioso del mundo del trabajo; un demócrata convencido no resignado. Un verdadero intelectual Público por sus discursos que no se refugiaban en el ámbito privado. Por todo ello, y por tantas cosas más, se nos aparece cotidianamente. Polémico, competitivo, querible, inteligente, provocador. Aludo a las improntas que deja su vida compleja, que escapa a su influjo. Su recuerdo es presente.

Recepción: 20/10/2021

Evaluado: 17/11/2021

Versión Final: 12/12/2021 